\title{
THE METHOD OF COORDINATES IN TEACHING ESP
}

\author{
Elena Solntseva \\ Saint Petersburg State University, Russia \\ E-Mail: e.solntseva@spbu.ru
}

\begin{abstract}
The article introduces a new approach to English language teaching and learning at media and journalism departments. It is called "the method of coordinates" and its purpose is to teach reading media, looking for author's intention and writing mass media texts. The method regards a mass media text as a multidimensional structure possessing such coordinates as protagonist, place, time, subject, author's intention, audience targeting, relevant external links, irrelevant external links, etc. Here a step-by-step analysis is described how to determine those in the text and thus observe the composition of the text. Further, the collected data are used to develop own writings in media. As an example, the report "Dalia Stasevska joins BBC Symphony Orchestra as principal guest conductor" from The Guardian (25.01.2019, by Imogen Tilden) is chosen. The novelty of the approach is in a particular combination of several steps while reading and analysing the content of a newspaper article. The method can be used in ESP classes at media and journalism departments while teaching students to read news articles and to analyse them semantically, pragmatically and structurally. It contributes to the development of reading skills and understanding author's intention as one of the most difficult tasks with the learners of English as a Second Language and prepares students to create personal writings in media.
\end{abstract}

Key words: ESP, English, reading skills, mass media

\section{INTRODUCTION}

Being one of the key skills in foreign language studies, reading and understanding author's intention is nevertheless the hardest issue with the learners of English as a Second Language. Reading and understanding are among the skills checked in state exams in Russia and abroad and it still evokes problems with students. Moreover, these skills are also of a great influence on learners' writing skills since it is where the communication begins.

In the paper, the new approach to teaching and learning English for Specific Purposesis introduced. It is aimed for ESP learners of upper intermediate or higher English level at media and journalism departments in institutions of higher professional education. A mass media text is described here as a part of mass media discourse. Mass media (or shortened media) are the main means of mass communication (broadcasting, publishing, and the Internet) regarded collectively. Mass media discourse is a part of modern mass media, it refers to the language and extra-materials that exist in media today (Dijk 2007; Dobrosklonskaya 2008; Chernyavskaya 2009).

Submitted September $15^{\text {th }}, 2019$, accepted for publication November $1^{\text {st }}, 2019$

(C) 2019 by University of Niš, Serbia | Creative Commons License: CC BY-NC-ND 
The approach here is called 'the method of coordinates' and its purpose is to teach reading media, looking for author's intention and writing mass media texts. The term 'coordinates' means pragmatic, semantic and syntactic parameters that a text possesses (Oller 1972, Finch 2000, Matthews 2007). The method of coordinates implies a step-by-step analysis of a mass media article with the aim to find these parameters and notice the composition of the analysed text. Further, the collected data are used to develop own writings in media. The methodology is developed consecutively from reading to writing. It includes observation, data collecting and experiment in learning foreign language (Grotjahn 1987, Brown 1988, van Lier 1988, Nunan 1992) where the students move from experimental design forward to qualitative and quantitative data examination and to interpretative analysis.

This method uses communicative strategy in teaching foreign languages with the focus on the functioning of a language in real situations (Woolley 2010; Spratt et al. 2011; Day et al. 2011), here namely in a situation of mass media communication. A stronger accent is put on applying language in written media. The method of coordinates is demonstrated on the example of a report from The Guardian, that is to say the genre-orientated method is used with the main focus on informative media genres (Reddick et al. 1999; Tertychny 2000; Scanlan 2002; Vorobjeva et al. 2015; Solntseva 2015). The novelty of the approach is therefore in a particular combination of several well-known steps while reading and analysing the content of a newspaper article. The method was first introduced and discussed at $1^{\text {st }}$ International Conference "Synergy of Languages and Cultures: Interdisciplinary Research" at Saint Petersburg State University in May 2019.

At a higher level of English instruction, especially at media and journalism departments, language skills are an integral part of a professional portfolio because the students apply their language in professional spheres to deal with quite specific tasks. It is of essential importance for the students of English for Specific Purposes at media and journalism departments since they not only read media texts but also write their own compositions which is, as often happens in the modern globalized media, in English. That is why the approach here combines language teaching and learning with domain teaching and learning (journalism) so that the final aim is to teach students to write news in foreign language.To use this approach, students should be aware of basics in media studies, so as to be familiar with the terms 'media', 'mass media discourse', 'media linguistics', 'journalistic genres', etc.

\section{NEW APPROACH: BACKGROUND}

\subsection{Communicative strategy in teaching foreign languages}

The method of coordinates is based on communicative strategy in teaching foreign languages. It pays attention to the usage and functioning of a language in context, in a real situation. The communicative approach considers the teaching of communicative competence as its goal, i.e. the ability to use language for constructive communication (Berns 1984, 5). After Jack C. Richards, communicative competence includes the following aspects of language proficiency:

- knowledge of how to use the language depending on the goals and functions of the utterance;

- knowledge of how to use the language in accordance with the situation and the participants (for example, when to use formal and informal speech); 
- the ability to create and understand various types of texts (for example, description, reports, interviews, conversations);

- the ability to maintain a conversation, despite limitations in language skills (for example, through the use of various types of communication strategies) (Richards 2006, 4).

Teaching a foreign language always means acquiring different skills that include reading, writing, listening, speaking. The method of coordinates focuses on reading as a starting point for writing. The reading process is based on the skill to establish connections between visual signs and their meaning which is sometimes hampered in a foreign language because of a weaker ability of non-native speakers to recognize stranger semantic connections.The existing techniques that can be used to improve reading skills include previewing, predicting, deducing meaning from context, understanding text structure, skimming, scanning, inferring (Spratt et al. 2011, 31), paraphrasing and visualization (Woolley 2010, 108-125).These are the strategies aimed to understand the information stated.

Moreover, reading plays an important role in the learning process as a learning tool. It helps in mastering linguistic material and its consolidation, ensures memorizing processes of lexical units, strenghtens the ability to find correlations between them, as well as to see the usage of grammatical phenomena, lexical structures and the word order in context. Reading also helps to improve speaking and writing skills as it evokes the cognitive processes of language acquisition and supplies the readers with visual examples of language patterns that can be later introduced in speech, written or oral (Spratt et al. 2011, 31).

However, special media and journalism departments require a different type of reading skills from their students because of the extraordinary demand of the field - not only to understand or enjoy the text, but more to get a very clear idea of what was said, how and why, this means to understand very profoundly the information itself and how it was presented, semantically, pragmatically and structurally. To this purpose, in the method of coordinates students do various tasks that include skimming and scanning. They serve as a background for further linguistic analysis of composition and structure in a mass media text.

\subsection{Mass media text structuring and composition}

The structure or the composition of a media article depends on its genre. The genre is a stable form or type of a journalistic work possessing similar substantial and formal features. In media, there is an established system of genres that includes informative, analytical and entertaining ones (Tertychny 2000). Informative genres occupy most space in newspapers, as well as in television and radio. They can be regarded as one of the most popular media form and serve as the best platform to practice for younger journalists in English.

Informative genres - a note, a report, an interview, to name a few, have a lot in common, first of all their aim being to inform people, not to comment, give an opinion or interact, but solely to give information, in an objective and unbiased way. Laconicism, the efficiency of reporting the event, is among their key features. In this case the purpose of the author is to inform the reader of the latest news as quickly as possible so the choice of language is also essential.

Besides, informative genres are distinguished by special methods of transmitting information: they focus on efficiency, capacity, compression, novelty of information and its social significance. In informative genres, the ability to see, select, evaluate, comment and respond quickly to new socially significant facts is important (Tertychny 2000).The most widespread informative text types differ in the following: 
- a note is a very brief, small message;

- a report is larger and it presents the information from the point of view of the participants;

- an interview is based on a conversation between a journalist and an interviewee, which is in general an interesting person for the audience.

Moving on to the differences of genres in the modern media, we can define them based on their structure. Generally, the informative media texts are being structured so that the key information comes first followed by details in a so called 'telegraph style' (Scanlan 2002). The informative genresanswer the questions 'What?', 'Who?','When?', 'Where?' and 'How?'. The larger the article, the more details it contains and to the more questions it responds. The principle is described as "inverted pyramid" (Scanlan 2002). A more profound investigation of genres can be found in some other works (Reddick et al. 1999; Tertychny 2000; Lorenz 2009), also with the focus on a magazine report (Solntseva 2015) or a travelling sketch (Vorobjeva et al. 2015).

In the modern media the extra-linguistic sources, such as photo, audio, video, hyperlinks, expand their functions by becoming integral parts in the news, and so influencing its structure. The text plus these extra elements create mass media discourse which is, in Russian tradition, mainly understood as a combination of different linguistic and extra-linguistic materials existing in the media (Dobrosklonskaya 2008). Media discourse stands above media text as the next language level.

Mass media discourse is defined by semantic coherence. Its basis is formed by semantic relations in the text on two levels: a local (between words and sentences) and a global one (thematic connections between the whole abstracts and texts) (Dijk 2007). In the case of modern electronic publications, this connection goes beyond the scope of individual texts, headings or publications, and tends further to the endless space of the Internet. At the level of discourse, another kind of relations is discovered, based on such characteristics of modern media as multimodality and hypertextuality. Multimodality means the opportunity of a media text to be expanded by photos or videos added to the text, that is, in mass media discourse a wide variety of information is presented - textual, audio and visual one (Chernyavskaya 2009). Hypertextuality as a way of organizing the Internet space where different units of information are combined creates multidimensional structure of media discourse. Multimodality and hypertextuality together ensure the presence of extralinguistic connections in journalistic articles and a large number of parameters existing in modern media (Solntseva 2018).

\section{THE METHOD OF COORDINATES}

\subsection{Subject of study}

As the structure of contemporary media is so diverse, it requires extraordinary methods of investigating. The new approach described here is based on the idea of mass media discourse including various parameters, or coordinates in all language spheres: semantics (relation to meaning), pragmatics (relation to author and audience) and syntax (relation to structure) (Oller 1972, Finch 2000, Matthews 2007). Semantic parameters include idea or topic of the article, participants, time and place. Pragmatic ones are author's style and audience-orientation. Syntactic parameters mean the length of the article and its structure or composition. In the text they may result in such coordinates as: 
- time

- place

- subject

- protagonist

- author's intention

- appealing to audience

- relevant hyperlinks

- video

- audio

- photo

- irrelevant hyperlinks

- advertisement, etc.

The investigating method consists of three main stages, from reading the initial text to writing an own one. Each stage has several steps. At first students read the article and find its coordinates, then they get accustomed to the usage of various vocabulary or grammar elements in the context, and in the end they have the task to use them again in their own articles, so that they not only acquire the knowledge of items introduced by native reporters but also put this knowledge into practice by applying it in personal writings.

The report "Dalia Stasevska joins BBC Symphony Orchestra as principal guest conductor" from The Guardian (25.01.2019, by Imogen Tilden) is chosen as an example. In the article, the career path of a young Finnish woman who got the position of a principal conductor in a British orchestra is described. The text also goes back to some moments in her life which contributed to her choice and success at work. Her quotes throughout the article demonstrate her views and mood.

At the first stage students are asked to read the text carefully, skimming it and looking for gist. Further they should apply scanning and mark the different coordinates with colours as follows. In the text hereunder different colours stand for different coordinates, the legend provided (see Table 1):

Dalia Stasevska joinsBBC Symphony Orchestraasprincipal guest conductor

\section{The 33-year-old Finn - a 'brilliant talent' - has onlybeen conducting} professionally

\section{Imogen Tilden}

\section{@ tildeni}
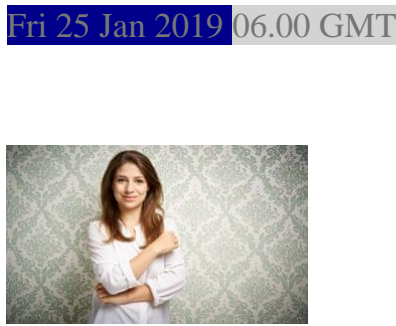

"Opera was my kind of punk" - conductor Dalia Stasevska, who joins the BBC Symphony Orchestra in July. Photograph: Jarmo Katila

The BBC Symphony Orchestra announces that Finnish conductor Dalitis
is to be the orchestra's principal guest conductor, filling a position that has



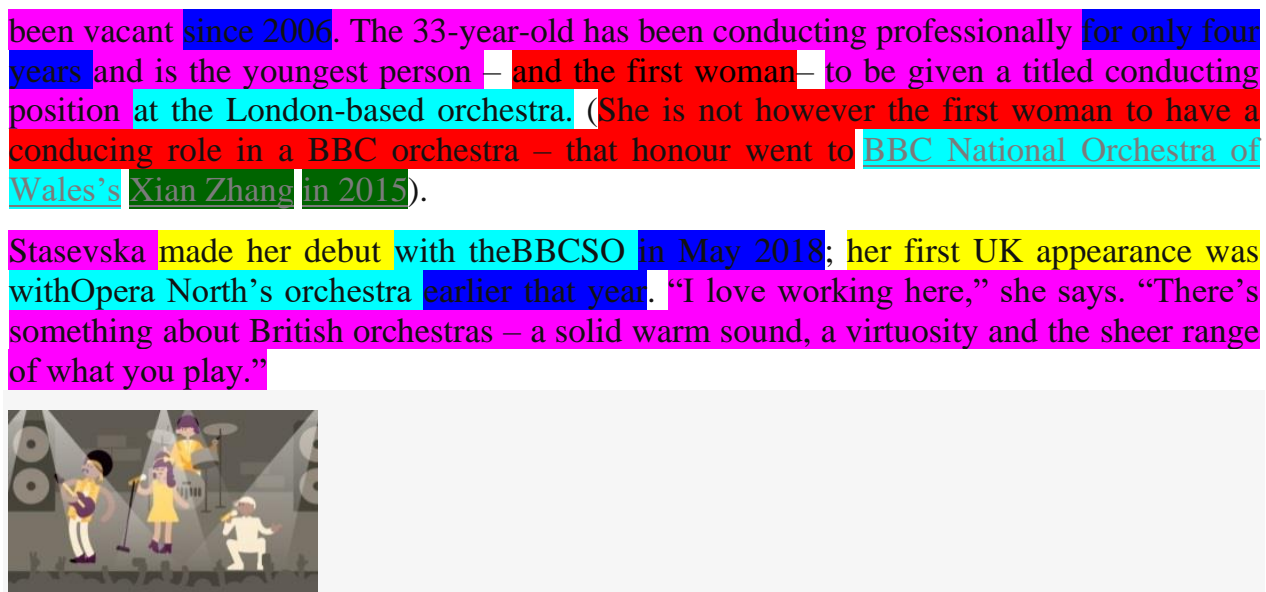

\section{Sign up for the Sleeve Notes email: music news, bold reviews and unexpected extras}

Read more

The UK might be lurching towards an uncertain future bu tshe says she didn't hesitate before agreeing to join the BBCSO. "Today, it's more important than ever that we have a space where everybody can come together and put their political views aside. Music is a place where worst enemies can sit side by side and feel the same thing."

Stasevska's original training was as a violinist. Discovering opera at age 13 opened up her eyes and ears to the richness of orchestral music. "Opera was kind of my punk," she says. "My friends were listening to the Spice Girls and Backstreet Boys, but I just wanted opera. Whenever we had to do some kind of show and tell at school about what interested us I would always talk about opera. People would boo me, but I'd say 'No! - Just listen to this magnificentmusic!' I knew it was special and I was happy to be different."
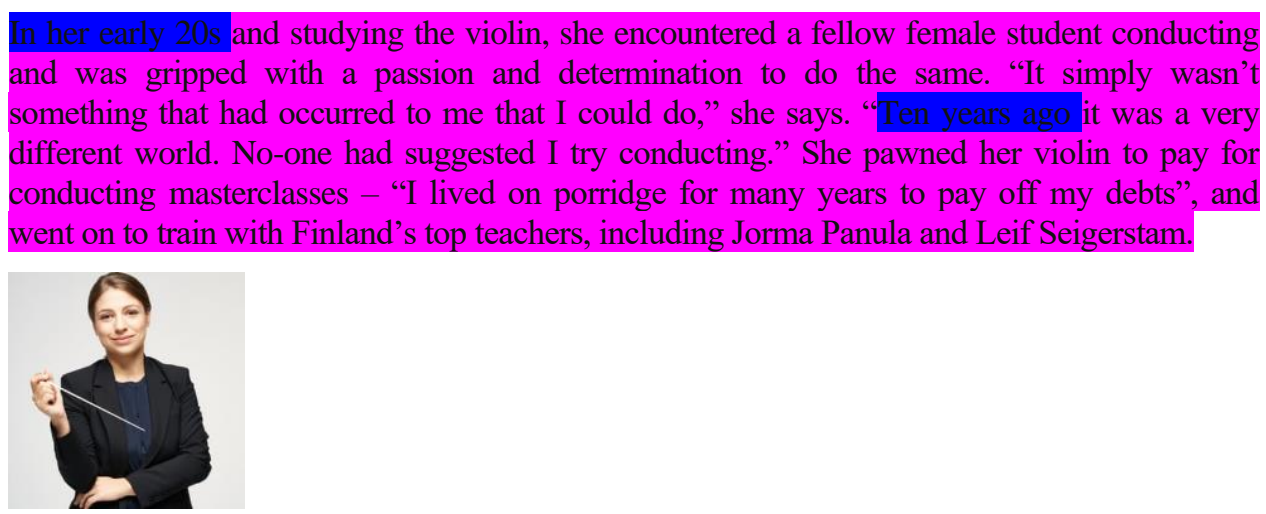

FacebookTwitterPinteres

"Ten years ago it was a very different world. No-one had suggested I try conducting". Dalia Stasevska. Photograph: Jarmo Katila 
"I had challenges, but I never thought about them in terms of female/male issues," she says.

she has worked with the Los Angeles Philharmonic, Gothenburg Symphony, Orchestra National de Lyon, Oslo Philharmonic and, her debut with the London Philharmonia in a contemporary programme.

BBCSO’s General Manager Paul Hughes was first introduced to Stasevska by her fellow Finn and the orchestra's chief conductor Sakari Oramo. He booked the young conducto to do two concerts, and rapidly realised he needed to snap up this 'brilliant talent'. "She communicates very naturally and easily with the musicians, and she knows exactly wha she wants," he said. "Her ability to balance core repertoire with new is a perfect fit for us Her youth and her musical outlook will have more impact than her gender. She will help us attract and engage a different community.

Stasevska has built a reputation for conducting a wide range of music but has a particular passion for 20th and 21 st century works, and is excited about technology and the opportunities it affords today's orchestras. Her husbandis also a musician - a compose and the bassist in the hugely successful power metal band Statovarius (and the great grandson of Sibelius). "He's the famous one, not me," she jokes. "There's no city or country where he doesn't get recognised!"

She cites Frida Kahlo and Leonard Bernstein as inspirations. "Kahlo was a strong woman who had full dedication to her art" and Bernstein for his omnivorous and joyful approach to music-making. "The way he thought out of the box is something I try to do. I want to put new energy into standard repertoire that we might take for granted and challenge audiences - and myself - to hear it as if for the first time.'

Stasevska is honoured to be an inspiration for new generations of female conductors, bu rubbishes the idea that conducting can be gendered and says she never felt disadvantaged because of her sex - "everyone has their own style". I don't like the term "feminist"sh says. "It means too many different things to different people. I prefer to talk about equality Everyone should be equal and have the same opportunities and access to music."

She makes her debut with the orchestra in her new role at the Proms

(The Guardian, 25.01.2019, by Imogen Tilden)

Table 1 Coordinates legend

\begin{tabular}{|l|l|}
\hline & Protagonists \\
Time \\
Place \\
$\square$ Subject \\
Related Photos \\
Related Hyperlinks \\
Author - Intention \\
Audience - Targeting \\
Technical Hyperlinks/Info \\
Irrelevant Information \\
\hline
\end{tabular}


In the report about Dalia Stasevska there can be seen the coordinates of protagonist, subject, time, place, related photos, related hyperlinks, author's intention, audience targeting, technical hyperlinks and irrelevant information. As it is evident from the Table 1 , most data given in the text are about the protagonist (in violet). The text also contains some extra materials like photos and hyperlinks (in dark green). At this stage students can see the article 'from above' with every linguistic and non-linguistic material that belongs to it. They perceive the story as a whole, as a set of different resources.

\subsection{Protagonist, subject, time and place}

After students have marked the coordinates they should also be given a task to find the expressions, words or sentences that reflect each of the outlined coordinates. This can be introduced as a 'fill in the table' task where the coordinates and their forms are presented as two columns respectively. At this stage students get an insight into media discourse resources at the author's disposal and how to use them. In the analysed article, among the main semantic parameters there are such characteristics as protagonist, subject, time and place. These coordinates can be found already in the heading and lead (in violet) which reflect the idea of putting the main piece of information in the first place of the text as in the inverted pyramid principle.

The analysis reveals that for instance the expressions "the 33-year-old Finn", "a brilliant talent", "Finnish conductor Dalia Stasevska", "the 33-year-old", "the youngest person - and the first woman - to be given a titled conducting position at the London-based orchestra" are used to refer to the protagonist and provide readers with the basic information thus answering the question 'Who?' as one of the key questions in informative media genres. As we can see in the text, they contain name, age, nationality and gender characteristics in noun-adjective complexes. The short forms like "the 33-year-old Finn" can supply a reader with full information about the protagonist in one utterance solely. There are also some other protagonists (a colleague, a rival and the husband) who are mentioned once, each in connection with Dalia Stasevska's life. Their characteristics are very short and limited with names.

The question 'What?' refers to the subject (in yellow), and the answers to it are the expressions "her debut", "her appearance", "her programme", "her new role". They are all nouns, or sometimes a noun and an adjective complex. These words related to the subject make clear Dalia's career steps. However the article does not contain a lot of references to the subject due to the stronger focus on the protagonist herself.

The expressions "for four years", "since 2006", "in 2015”, "in May 2018”, "earlier that year", "today", stand for time (in blue). They are expressed by time adverbs and establish chronological connections throughout the text. We may follow the career development of the protagonist, Dalia Stasevska, from the past to the present.

When dealing with place (in turquoise), the author introduces "BBC Symphony Orchestra", "the London-based orchestra", "BBC National Orchestra of Wales's", "Opera North's orchestra", "the UK'. They answer to the question 'Where?' The nouns mentioned can undoubtedly determine the scene as the United Kingdom, London and their orchestras.

Sometimes the coordinates overlap in a single expression, for instance "her first UK appearance in a contemporary programme" refers to the subject (her appearance in a programme), place (UK) and time (first; contemporary) altogether. The overlapping lets the author provide readers with some intermediate conclusions or remind quickly of some essential data. 


\subsection{Extra-linguistic sources}

Apart from the main information introduced first and constantly repeated in the whole text, there are also some extra elements as the modern media text is not only a text but more of a mass media discourse, a combination of the text and other non-linguistic sources, too. The sources can be relevant or irrelevant, depending on their semantic correlation with the main topic in the article. Among the relevant extra-linguistic sources we may distinguish photos (in light green) and hyperlinks (in dark green). The two photos provide readers with the two styles of Dalia Stasevska, first presenting her as she discovered opera for herself: "Opera was my kind of punk" - conductor Dalia Stasevska, who joins the BBC Symphony Orchestra in July. The second photo has the image of a more seriously looking woman holding a conductor's baton with the caption "Ten years ago it was a very different world. No-one had suggested I try conducting": Dalia Stasevska. Comparing these two photos can be an additional way for the author to show the changes in the protagonist's life and career. Both captions contain the quotes of Dalia Stasevska which also stand for the author's intention to be personal, not neutral, in characterizing her.

Relevant hyperlinks let the readers know more about the protagonists: Dalia Stasevska, her rival BBC National Orchestra of Wales's Xian Zhang, the orchestra's chief conductor Sakari Oramo and Dalia's husband. Some links also have a connection to social networks (Facebook, Twitter, Pinterest). The hyperlinks lead to external resources, connect the initial piece with a number of other web-sites, thus expanding the informational volume of the article and turning the text into an infinite multidimensional discourse structure.

Irrelevant extra-linguistic sources (in grey) add to the relevant ones the possibilities of signing up for newsletters and learning more about the issue: "Sign up for the Sleeve Notes email: music news, bold reviews and unexpected extras", "Read more". It uses imperative mood (sign up) and epithets (bold, unexpected) to attract attention. Interestingly, the advertisement for subscription is aimed to music fans so that it offers music news first and possesses a picture of a band. Irrelevant resources, especially commercials, are an integral part of modern media. They draw readers' attention to goods and services that have only little or even nothing in common with the topic of the article.

\subsection{Pragmatic coordinates}

Further, apart from the semantic coordinates of protagonist, time, place, subject, relevant and irrelevant sources, we distinguish some pragmatic parameters in the text that correlate with the author and audience. These are audience targeting (in sea green) and author's intention (in red). To identify them remains one of the key difficulties with language learners and examinees.

Dalia appeals to audience in her quotes: "People would boome, but I'd say 'No! - Just listen to this magnificent music!' and 'I want to put new energy into standard repertoire that we might take for granted and challenge audiences - and myself - to hear it as if for the first time." She introduces an imaginary dialogue where she is inclined to state her position independent of people's opinion. This provokes a stronger contact of the written text and its readers, moving them to a possible discussion in social networks as the links to Facebook, Twitter or Pinterest, are also among the relevant extra-linguistic sources. 
Besides, we cannot omit one extra idea which is subsequently introduced by the author throughout the article and uses the story of Dalia Stasevska's career path as a background. The achievement of a woman seems for the author to be the best frame to develop the feminist concept. Starting with the lead ("The 33-year-old has been conducting professionally for only four years and is the youngest person - and the first woman - to be given a titled conducting position at the London-based orchestra."), the author mentions the feminist topic here and there in the whole text: "Stasevska is honoured to be an inspiration for new generations of female conductors, but rubbishes the idea that conducting can be gendered...I don't like the term "feminist" she says. "It means too many different things to different people. I prefer to talk about equality. Everyone should be equal and have the same opportunities and access to music." The words "the first woman, female, gender, feminist, equality, equal" appear in several cases constantly reminding readers about what the story actually is.

The other topic being developed here in the article touches upon political situation in the UK. As one of the most frequently discussed questions those days, it could not be left without attention, so the author mentions it casually moving on to the protagonist: "The UK might be lurching towards an uncertain future but she says she didn't hesitate before agreeing to join the BBCSO." Moreover, the sentences "Today, it's more important than ever that we have a space where everybody can come together and put their political views aside. Music is a place where worst enemies can sit side by side and feel the same thing." might in a sense be regarded as a conclusion and reveal the author's intention to restrain from politics through music.

Author's intention is semantically connected with the topic of the article, but stands above the topic mentioned and uses it as a background. Pragmatically, the author wants to introduce his very clear position in the complicated up-to-date topic of gender and feminism. On the other hand, he cannot put aside the political problems of the day and seizes the opportunity to mention it. These pragmatic coordinates are the most puzzling to find, that is why students must look for audience targeting and author's intention as the last step, after all other coordinates have been determined. In this case, they must be given a very clear explanation of the course of action.

\subsection{Table of coordinates}

As it was mentioned above students work with the coordinates doing the 'fill in the table' task where they fill a table of different language resources used for every coordinate. The resources presented in this graphic form let the students visualize the expressions and remember them easily for further usage in personal writings. The table to fill in can look like this (see Table 2).

Additionally, to practice the usage of some new or more difficult expressions, the students can also deal with the task of composing a similar part of a journalistic text, for example, a sentence or an abstract based on some other news topic (for example: The 24year-old American has won this year's Miss Virginia competition). Thus, they learn to apply new vocabulary in the right context which matters extremely with students of lower vocabulary skills. 
Table 2 Coordinates and their form

\begin{tabular}{|c|c|}
\hline Coor & orm \\
\hline protagonist & $\begin{array}{l}\text { "the 33-year-old Finn", "a "brilliant talent'”, "Finnish conductor Dalia } \\
\text { Stasevska", "the 33-year-old", "the youngest person-and the first woman- } \\
\text { to be given a titled conducting position at the London-based orchestra" etc. }\end{array}$ \\
\hline subject & "her debut", "her appearance", "her programme", "her new role" \\
\hline time & $\begin{array}{l}\text { "for four years", "since 2006”, "in 2015”, "in May 2018”, "earlier that } \\
\text { year", "today" }\end{array}$ \\
\hline place & $\begin{array}{l}\text { "BBC Symphony Orchestra", "the London-based orchestra", "BBC National } \\
\text { Orchestra of Wales 's", "Opera North's orchestra", "the UK" }\end{array}$ \\
\hline udie & $\begin{array}{l}\text { "People would boo me, but I'd say 'No! - Just listen to this magnificent } \\
\text { music!' and "I want to put new energy into standard repertoire that we might } \\
\text { take for granted and challenge audiences - and myself - to hear it as if for the } \\
\text { first time." }\end{array}$ \\
\hline then & $\begin{array}{l}\text { "The 33-year-old has been conducting professionally for only four years and } \\
\text { is the youngest person - and the first woman - to be given a titled conducting } \\
\text { position at the London-based orchestra." } \\
\text { Stasevska is honoured to be an inspiration for new generations of female } \\
\text { conductors, but rubbishes the idea that conducting can be gendered. } \\
\text { "...I don't like the term "feminist" she says. "It means too many different } \\
\text { things to different people. I prefer to talk about equality. Everyone should be } \\
\text { equal and have the same opportunities and access to music." }\end{array}$ \\
\hline $\begin{array}{l}\text { autho } \\
\text { inten }\end{array}$ & $\begin{array}{l}\text { The UK might be lurching towards an uncertain future but she says she didn't } \\
\text { hesitate before agreeing to join the BBCSO." } \\
\text { "Today, it's more important than ever that we have a space where everybody } \\
\text { can come together and put their political views aside. Music is a place where } \\
\text { worst enemies can sit side by side and feel the same thing." }\end{array}$ \\
\hline
\end{tabular}

\subsection{An insight into composition}

As the next step, students look at the composition of the article marking the coordinates according to their place in the article. The analysed article consists of a heading, a lead, 12 paragraphs and some extra resources. The coordinates of the text build up the structure and the composition as follows (semantically essential coordinates in each paragraph are in bold):

Heading: protagonist, place

Lead: protagonist, time, place

Irrelevant link (to the author of the article)

Relevant photo

Relevant photo caption - quote

Irrelevant information (photographer's name)

Paragraph 1: place, protagonist, time, author's intention 1 (gender), extra links (protagonist 2 - rival)

Paragraph 2: protagonist, subject, place, time

Irrelevant photo, advertisement to subscribe

Paragraph 3: author's intention 2 (politics), place, time 
Paragraph 4: protagonist, audience targeting

Paragraph 5: time, protagonist, place

Relevant photo

Relevant link to social networks

Relevant photo caption - quote, time

Irrelevant information (photographer's name)

Paragraph 6: protagonist, author's intention 1

Paragraph 7: time, subject, place

Paragraph 8: place, time, extra link (protagonist 3- colleague), protagonist, author's

intention1

Paragraph 9: protagonist, time, place, extra link (protagonist 4- husband)

Paragraph 10: protagonist, audience targeting

Paragraph 11: protagonist, author's intention 1

Paragraph 12: protagonist, subject, place, time

Looking at this composition, students can get a clearer understanding of the structure in a news article. For instance, the heading and lead contain only key coordinates of the protagonist, place and time whereas the paragraphs 1, 6, 8 and 11 reveal the first author's intention (a speculation on gender issues). The author's intention 2 (a slight mention of politics) is placed at the beginning of the article and hardly plays crucial role in the whole story. Extra resources or the irrelevant ones (advertisement in particular) are placed in the first half of the text so as to attract more attention from readers.

Semantically the strongest paragraph is number 8 that contains the most of all relevant coordinates. It is here where the author puts the characteristic "brilliant talent" which is first mentioned in the lead. Thus the connection between the start and the end of the story is established. The strongest focus on the author's intention 1 is introduced in the paragraph 11 . The paragraph 12 contains the key coordinates alonein the same sentence which serves as a conclusion. An insight into composition provides students with their own pattern of a journalistic text, here of a report. They can use this pattern while structuring own writings and creating other informative texts in media.

\subsection{Course of action}

In the method of coordinates in general, the following actionsareundertaken for media text analysis and further for development of personal writings and news creation:

1. Read the text carefully applying skimming, looking for gist.

2. Read the text again using scanning, looking for different coordinates, mark them with colours.

3. Determine the coordinates of protagonist, subject, time and place given in the text. Fill in the table with the correspondent expressions (see Table 2 above).

4. Determine the coordinates of relevant extra-linguistic resources, for example, photos, hyperlinks, etc.

5. Determine the coordinates of irrelevant extra-linguistic sources, for example, advertisement.

6. In the rest, find the coordinates that refer to pragmatics: audience targeting, for example appealing to readers, and author's intention, piece of information that does not belong to other groups. Author's intention is semantically connected with the topic of the article but stands above the topic mentioned using it as a background. Fill in the table with the correspondent expressions. 
7. If necessary depending on English level: practice using some of new expressions by making upown sentences or abstracts on different topics.

8. Mark the article structure as a composition scheme (see paragraph 5).

9. Apply the same vocabulary and structure while writing a similar article on some other news topic.

The steps listed above can help teachers to put goals for students and follow the method of coordinates step by step. After having applied the method students get a new pattern to write their own journalistic text of informative genre in English.

\section{CONCLUSION}

Being a reporter or a journalist means constant challenge in finding news and transferring them in a quick and unique way, knowing how to apply every possible both linguistic and extra-linguistic source. It requires from students to learn different models of news presentation, which can be successfully done with the method of coordinates as demonstrated above, as it is useful for writing texts in English within the modern globalized media. The method of coordinates reveals a set of semantic, pragmatic and structural characteristics of a journalistic text. Learning these parameters the students of English for Specific Purposes at media or journalism departments understand better how a news article is made and what sources it requires.

Here a mass media text is regarded as a part of mass media discourse, a multidimensional structure possessing such coordinates as protagonist, place, time, subject, author's intention, audience targeting, relevant external links, irrelevant external links, etc. The proposed methodology presentation provides a step-by-step analysis of these coordinates in a modern media text which mean sunderstanding text composition, author's intention and expressions used. In the end, students get accustomed to the structure, as well as to vocabulary of a news article and are able to begin their personal writings. This approach also contributes to the development of reading skills and understanding author's intention as one of the most difficult tasks with the learners of English as a Second Language.

\section{REFERENCES}

Berns, M. S. 1984. Functional approaches to language and language teaching: Another look. In S. Savignon \& M. S. Berns (Eds.), Initiatives in communicative language teaching. A book of readings. Reading, MA: Addison-Wesley. Pp. 3-21.

Brown, J. D. 1988. Understanding Research in Second Language Learning. A Teacher's Guide to Statistics and Research Design. New York: Cambridge University Press.

Chernyavskaya, V. E. 2009. Text Linguistics: Multimodality, Intertextuality, Interdiscursivity. Moscow.

Day, J., Krzanowski, M. 2011. Teaching ESP for Specific Purposes: An Introduction. Cambridge University Press.

Dijk, T. A. 2007. The Study of Discourse: an Introduction. In: Discourse Studies. 5 vols. London.

Dobrosklonskaya, T. G. 2008. Media Linguistics: Systematic Approach to Mass Media Language Studies. Moscow.

Durkin, D. 2004.Teaching them to read (6th ed.). Boston: Pearson. 
Finch, G. 2000. Linguistics: The Main Branches. In: Linguistic Terms and Concepts. Palgrave Study Guides. Palgrave, London.

Grotjahn, R. 1987. On the Methodological Basis of Introspective Methods. In C. Faerch, G. Kasper (eds.) Introspection in Second Language Research. Clevedon Avon, England: Multilingual Matters.

Lier van, L. 1988. The Classroom and the Language Learner. London: Longman.

Lorenz, D. 2009. Journalismus. Weimar.

Matthews, P.H. 2007. The Concise Oxford Dictionary of Linguistics (3 ed.). Oxford University Press.

Nunan, D. 1992. Research methods in language learning. Cambridge University Press.

Oller, J. On Relation between Syntax, Semantics and Pragmatics. In: Linguistics. Vol.10. Pp.43-55.

Reddick, R. 2001.The Online Journalist: Using the Internet and Other Electronic Resources. In: R. Reddick, E. King; ed. S. Dalphin. 3th. ed., Fort Worth: Harcourt College Publishers.

Richards, J. C. 2006.Communicative Language Teaching Today. Cambridge University Press.

Scanlan, C. 2002.Workbook to Accompany Reporting and Writing Basics for the 21st Century. OUP.

Solntseva, E. 2015. Magazine Report in Modern Mass Media Discourse (linguistic studies of German texts). Thesis Summary. Saint Petersburg State University, 2015.

Solntseva E. 2018. Types of Coherence in Mass Media Discourse. Vestnik of Saint Petersburg University. Language and Literature. Volume 15. Issue 3. Pp.481-491

Spratt, M., Pulverness, A., Williams, M. 2011. The TKT Course. Modules 1,2,3. Cambridge University Press.

Tertychny, A. A. 2000. Periodicals genres: manual.Moscow: Aspekt Press.

Vorobjeva, L. V., Kazakova, O. A., Frik T. B. 2015.Journalistic Texts in Training Russian as Foreign Language: Genre-Orientation Approach. Procedia - Social and Behavioral Sciences 215 (2015). Pp.112-117.

Woolley, G. 2010. Developing reading comprehension: Combining visual and verbal cognitive processes. Australian Journal of Language and Literacy, 33 (2). Pp.108-125. 